\title{
Nutritional Interventions on Physical Functioning for Critically III Patients: An Integrative Review
}

\author{
Wendie Zhou ${ }^{1,2, *}$ \\ Suebsarn Ruksakulpiwat iD ${ }^{3, *}$ \\ Yuying Fan ${ }^{1,2}$ \\ Lingling $\mathrm{ji}^{4, *}$ \\ 'Clinical Nursing Teaching Department, \\ The Second Affiliated Hospital of Harbin \\ Medical University, Harbin, People's \\ Republic of China; ${ }^{2}$ Office of General \\ Affairs, School of Nursing, Harbin \\ Medical University, Harbin, People's \\ Republic of China; ${ }^{3}$ Department of \\ Medical Nursing, Faculty of Nursing, \\ Mahidol University, Bangkok, Thailand; \\ ${ }^{4}$ Department of Pediatrics, The Second \\ Affiliated Hospital of Harbin Medical \\ University, Harbin, People's Republic of \\ China \\ *These authors contributed equally to \\ this work
}

Background: Poor physical functioning (PF) is a common issue among critically ill patients. It was suggested that reasonable nutrition accelerates PF recovery. However, the details and types of nutritional interventions on the PF of different intensive care unit (ICU) patients at present have not been well analyzed yet. This study aimed to systematically synthesize nutritional interventions on PF in different ICU populations.

Methods: Whittemore and Knafl's framework was employed. PubMed, EMBASE, Web of Science, CINAHL Plus with Full Text, and Cochrane Library were searched to obtain studies from January 2010 to September 2020, with a manual search of the included studies' references. Record screening, data extraction, and quality appraisal were conducted independently by each reviewer before reaching an agreement after discussion.

Results: Twelve studies were included reporting the effects of early parenteral nutrition, early enteral nutrition, early goal-directed nutrition, early adequate nutrition, higher protein delivery, higher energy delivery, low energy delivery, energy and protein delivery, intermittent enteral feeding on PF like muscle mass, muscle strength, and function. Function was the most common outcome but showed little improvements. Muscle strength outcomes improved the most. The mechanically ventilated were the most popular target ICU population. The commenced time of the interventions is usually within 24 to 48 hours after ICU admission. Conclusion: Research on nutritional interventions on critically ill patients' PF is limited, but most are of a high level of evidence. Few intervention studies specified their evidence basis. Qualitative studies investigating timeframe of initiating feeding, perspectives of the patients' perspectives and caregivers are warranted to advance research and further discuss this topic.

Keywords: nutrition, physical functioning, intensive care units

\section{Introduction}

Physical functioning (PF) is the physical abilities allowing functional independence and those related to movement. ${ }^{1}$ Poor PF, including decreased muscle mass, muscle strength, and function, is a frequent problem in critically ill patients, ${ }^{2-4}$ since skeletal muscle proteolysis is enhanced due to the catabolism caused by the hypermetabolic state of acute illness, ${ }^{5,6}$ which is associated with adverse clinical outcomes including infections, difficult weaning from mechanical ventilation (MV), a longer length of stay, increases mortality, higher financial costs, decreased quality of life of survivors. ${ }^{4,7}$ Rapid muscle loss is independently correlated with increased intensive care unit (ICU) mortality and in-hospital mortality in ICU patients. ${ }^{8} \mathrm{~A}$ study suggested that decreased PF was defined as the most critical outcome by ICU survivors, ${ }^{9}$ who often experience permanent functional disability due to ICU-
Correspondence: Yuying Fan

Email fanfanfensituan@|26.com 
acquired weakness (ICU-AW).$^{10}$ These, along with skeletal muscle's immunologic and metabolic functions, highlight the importance of preserving muscle mass and promoting PF during acute illness. ${ }^{11,12}$ Moreover, as Herridge pointed out, surviving critical illness is not the happy ending we imagined for our patients. ${ }^{13}$

Besides, ICU patients often have difficulty eating independently and are at high risk of malnutrition and lean body mass loss, ${ }^{14}$ rendering them needing nutritional support most frequently among all patients. ${ }^{15}$ It was found that optimal amounts and timely provision of nutritional intake relate to faster PF recovery and reduced infectious complications, time of $\mathrm{MV}$, and mortality. ${ }^{16-19}$ Reasonable nutrition is fundamental for ICU patients to maximize physical programs' benefits and support recovery. ${ }^{14}$ While inadequate nutritional therapy results in loss of lean body mass, lack of adequate physical activity leads to muscle weakness and inability to mobilize. ${ }^{20}$ Nevertheless, it is quite challenging to plan the right nutritional intervention for ICU patients. ${ }^{15}$ The best way of performing nutritional therapy remains controversial. ${ }^{21}$ Even though there are several nutritional guidelines specialized for the critically ill, such as the guidelines of the European Societies for Clinical Nutrition and Metabolism (ESPEN) (2018), ${ }^{22}$ the European Society of Intensive Care Medicine (ESICM) (2017), ${ }^{23}$ and the Society of Critical Care Medicine (SCCM) and American Society for Parenteral and Enteral Nutrition (A.S.P.E.N.) (2016), ${ }^{24}$ adherence to these standards in clinical practice is limited. There is a significant discrepancy among nutritional interventions, hindering the interpretation of results, comparisons of trials, and the formation of strong evidencebased recommendations. ${ }^{21,25}$ Furthermore, as a patientcentered outcome, PF outcomes are vital in clinical trials evaluating nutritional interventions. ${ }^{26}$ These speak to the significance of understanding what types of nutritional interventions have been implemented on the PF (eg, muscle mass, muscle strength, function) of different categories of ICU patients at present, to provide a reference for clinical practice and future research design and promote the functional ability of the critically ill.

The effects of certain specific types of nutritional interventions in ICU patients, such as enteral nutrition, parenteral nutrition (PN), energy, and protein delivery, etc., were explored by several systematic reviews as well as meta-analyses, ${ }^{7,27-29}$ with some targeting PF while others the overall clinical outcomes (with or without PF). However, to our knowledge, almost none described and summarized the various types of nutritional interventions of this topic across studies, hindering better understanding and future design of the nutritional interventions on the PF for ICU patients.

This integrative review aims to identify and analyze details of different nutritional interventions on PF for critically ill patients with different characteristic (eg, with organ failure, contradictions of enteral nutrition (EN), etc.) over the past decade. So as to benefit the critically ill more instead of simply helping them survive the critical illness.

\section{Methods \\ Design}

This review was guided by Whittemore and Knafl's framework $^{30}$ for integrative reviews, which is composed of five steps: (1) problem identification, (2) literature search, (3) data evaluation, (4) data analysis, and (5) presentation. The Preferred Reporting Items for Systematic Reviews and Meta-Analyses (PRISMA) ${ }^{31}$ were applied to present the flow diagram of the identification, screening, exclusion, and inclusion of the literature. Abstracts, conference proceedings, dissertations, commentaries, nonpeer-reviewed journal articles, research protocols, case reports, reviews (not including systematic reviews and meta-analyses), and researches that did not study $\mathrm{PF}$ were excluded. According to ICF framework, ${ }^{32}$ which was introduced by the World Health Organization (WHO) to provide a unified and standard language for the description of health and health-related well-being, ${ }^{1}$ $\mathrm{PF}$ is composed of muscle mass, muscle strength, and function. ${ }^{33}$ Muscle mass is a passive nonvolitional outcome enabling quantification of muscle morphology. ${ }^{33}$ Muscle strength, as a dynamic measure, provides greater detail on the patient's level of impairment. ${ }^{33}$ Function reflects activity limitation within the ICF framework. ${ }^{33}$ If the intervention topic of the sub-analysis of one trial was the same as the original trial, it would be combined with the original trial and treated as one (eg, trial $\mathrm{A}+$ subanalyses $\mathrm{B}, \mathrm{C}$ of trial $\mathrm{A}=$ trial $\mathrm{A}$ ). The details of the inclusion and exclusion criteria of this research are provided in Table 1.

Five electronic databases were included in this integrative review: PubMed, EMBASE, Web of Science, 
Table I Inclusion and Exclusion Criteria

\begin{tabular}{|c|c|}
\hline Inclusion Criteria & Exclusion Criteria \\
\hline - Human patients $\geq 18$ years of age & $\begin{array}{l}\text { - Conference proceedings, dissertations, commentaries, non-peer } \\
\text { reviewed journal articles, research protocols, pilot studies, case } \\
\text { reports, reviews (except systematic reviews and meta-analyses) }\end{array}$ \\
\hline - Patients receiving treatment in the ICU & $\begin{array}{l}\text { - Combined with other types of interventions (eg, exercise, electrical } \\
\text { stimulation) }\end{array}$ \\
\hline $\begin{array}{l}\text { - Featured a nutritional intervention, which is defined in this study as I) } \\
\text { route of administration: enteral nutrition, parenteral nutrition; 2) the } \\
\text { administration of non-pharmacological/non-immune-modulating } \\
\text { agents: calories, protein, micronutrients, micronutrients etc.; 3) tim- } \\
\text { ing for initiation of feeding; 4) continuous or intermittent feeding; and } \\
\text { 5) feeding speed and amount }{ }^{15,26,73,74}\end{array}$ & $\begin{array}{l}\text { - Exploring the effects of any of I) pharmacological agents: insulin, } \\
\text { growth hormone, ghrelin agonists, anabolic steroids etc.; 2) immune- } \\
\text { modulating agents: glutamine, selenium, fish oil, zinc, vitamin D etc.; 3) } \\
\text { antioxidants: vitamin C, vitamin E etc.; and 4) monitoring/management } \\
\text { of nutritional effects: GRV, gastrointestinal syndrome (diarrhea, } \\
\text { abdominal distension, abdominal pain, nausea or vomiting, etc.), blood } \\
\text { electrolytes (potassium, magnesium etc.) etc. }\end{array}$ \\
\hline $\begin{array}{l}\text { - Reported a physical functioning outcome, including muscle mass, } \\
\text { muscle strength (eg, muscle wasting, muscle weakness, fatigue, hand } \\
\text { grip etc.), function (eg, walk, daily living tasks, etc.) })^{21,33}\end{array}$ & \\
\hline - Reported in English language & \\
\hline
\end{tabular}

Abbreviations: ICU, intensive care unit; GRV, gastric residual volume.

CINAHL Plus with Full Text, and Cochrane Library, with time-limited from January 2010 to September 2020. Reference lists of the included studies were manually searched. Subject headings, key terms, and the complete search strategy can be accessed in Supplementary File 1.

\section{Data Extraction and Quality Appraisal}

The level of evidence (LOE) for each study was evaluated independently by two researchers (WZ and SR) using the Rating System for the Hierarchy of Evidence for Intervention and Treatment Questions by Melnyk and Fineout-Overholt. ${ }^{34}$ The LOE of the literature is designated as follows: systematic reviews or meta-analyses of randomized controlled trials (RCT), and clinical guidelines based on systematic reviews or meta-analyses (Level 1); well-designed RCTs (Level 2); controlled trials with no randomization (Level 3); case-control or cohort study (Level 4); systematic reviews of descriptive and qualitative studies (Level 5); single descriptive or qualitative study (Level 6); expert opinions (Level 7) (not included in this review). ${ }^{34}$

\section{Data Analysis}

The articles were classified into a literature matrix that included author, year, country, duration, design, commenced time, total sample size, target population, description of the intervention, PF measure, finding, and level of evidence.

\section{Results}

\section{Article Characteristics}

An initial search of the literature generated 3109 articles. A total of 12 articles were included in this integrative review after final screening and quality appraisal. The PRISMA checklist ${ }^{31}$ was utilized to outline the retrieval process (see Figure 1).

Almost $84 \%(n=10)$ of included studies were published from 2015 to 2020 . Four $(30.77 \%)$ studies were conducted in Australia, one (7.69\%) was conducted in New Zealand, Belgium, Japan, United States, Denmark, United Kingdom, and China each, and two (15.38\%) not applicable. The numbers of studies conducted in singlecenter and multi-center settings were both five (41.67\%).

Article types consisted of six (50\%) randomized controlled trials, three (25\%) descriptive studies, two (16.67\%) systematic reviews, and one (8.33\%) non-randomized control trial. One hundred to two hundred $(\mathrm{n}=4,33.33 \%)$ was the common sample size of study followed by 0 to $100(n=3$, $25 \%)$, above $1000(\mathrm{n}=2,16.67 \%)$, and 200 to $1000(\mathrm{n}=1$, $8.33 \%)$. The LOE of the articles was two (16.67\%) for Level 1, six (50\%) for Level 2, one (8.33\%) for Level 3, and three (25\%) for Level 6 (see Table 2). 


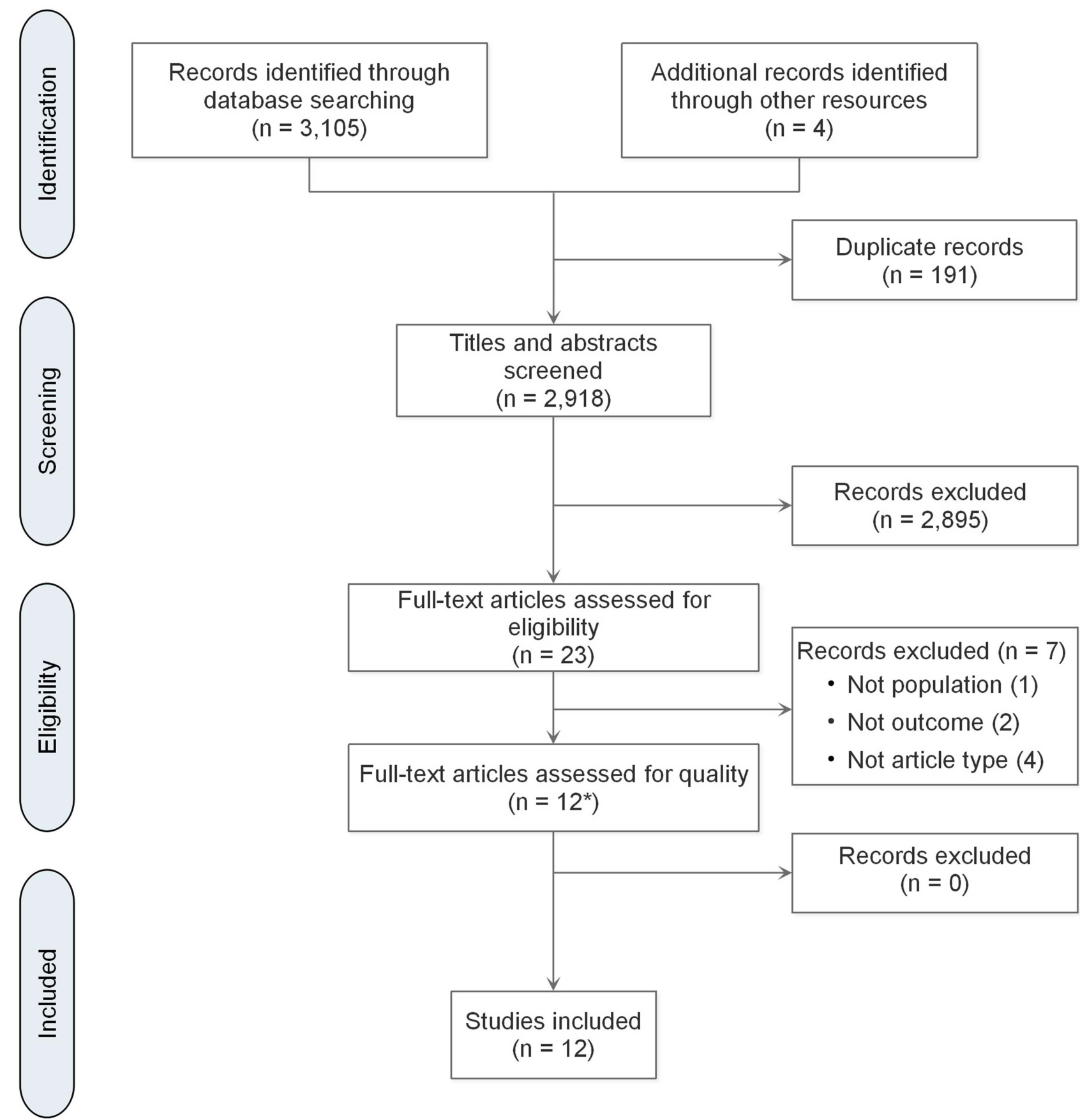

Figure I PRISMA flow chart. *Original Early Parenteral Nutrition Completing Enteral Nutrition in Adult Critically III Patients (EPaNIC) study and four sub-analyses of it were treated as one EPaNIC study. Notes: PRISMA figure adapted from Liberati A, Altman D, Tetzlaff J, et al. The PRISMA statement for reporting systematic reviews and meta-analyses of studies that evaluate health care interventions: explanation and elaboration. Journal of clinical epidemiology. 2009;62(I0). Creative Commons. ${ }^{31}$

\section{Participant Characteristics}

The target population in the included studies were ICU patients with mechanically ventilated $(\mathrm{n}=6$, $50.00 \%)$, chronic critical illness $(\mathrm{n}=1,8.33 \%)$, relative contraindications to early EN ( $\mathrm{n}=1,8.33 \%)$, and a requirement of PN ( $\mathrm{n}=1,8.33 \%$ ) (see Table 2$)$. Three $(25.00 \%)$ articles included all types of ICU patients.

\section{Synthesis of Interventions, Outcomes, and Results \\ Description of Nutritional Interventions}

Altogether, nine nutritional interventions were evaluated in 12 studies. Table 2 shows that the majority of nutritional intervention type is early PN $(\mathrm{n}=2,16.67 \%)$ and low energy delivery $(\mathrm{n}=2,16.67 \%)$. Other interventions like 
Table 2 The Characteristics of Included Studies

\begin{tabular}{|c|c|c|}
\hline Characteristic & Number & $\begin{array}{l}\text { Percentage } \\
\text { (\%) }\end{array}$ \\
\hline \multicolumn{3}{|l|}{ Publication year } \\
\hline $2015-2020$ & 10 & 83.33 \\
\hline $2010-2014$ & 2 & 16.76 \\
\hline \multicolumn{3}{|l|}{ Country of origin } \\
\hline Australia & 4 & 30.77 \\
\hline New Zealand & I & 7.69 \\
\hline Belgium & I & 7.69 \\
\hline Japan & I & 7.69 \\
\hline United States & I & 7.69 \\
\hline Denmark & I & 7.69 \\
\hline United Kingdom & I & 7.69 \\
\hline China & I & 7.69 \\
\hline$N / A$ & 2 & 15.38 \\
\hline \multicolumn{3}{|l|}{ Location of study } \\
\hline Single-center & 5 & 41.67 \\
\hline Multi-center & 5 & 41.67 \\
\hline$N / A$ & 2 & 16.66 \\
\hline \multicolumn{3}{|l|}{ Study design } \\
\hline $\mathrm{RCT}$ & 6 & 50.00 \\
\hline Descriptive study* & 3 & 25.00 \\
\hline Systematic review & 2 & 16.67 \\
\hline Non-randomized control trial & I & 8.33 \\
\hline \multicolumn{3}{|l|}{ Sample size } \\
\hline $0-100(39)$ & 3 & 25.00 \\
\hline$>100-200$ & 4 & 33.33 \\
\hline$>200-1000$ & I & 8.33 \\
\hline$>1000$ & 2 & 16.67 \\
\hline N/A & 2 & 16.67 \\
\hline \multicolumn{3}{|l|}{ Commenced time } \\
\hline Within 24 hours after ICU admission & 3 & 23.08 \\
\hline Within 48 hours after ICU admission & 3 & 23.08 \\
\hline Within 72 hours after ICU admission & 2 & 15.38 \\
\hline Unspecified & 3 & 23.08 \\
\hline Others & 2 & 15.38 \\
\hline \multicolumn{3}{|l|}{ Target ICU population } \\
\hline Mechanically ventilated** & 6 & 50.00 \\
\hline Chronic critical illness & 1 & 8.33 \\
\hline $\begin{array}{l}\text { Relative contraindications to early } \\
\text { enteral nutrition (EN) }\end{array}$ & 1 & 8.33 \\
\hline $\begin{array}{l}\text { A requirement of parenteral } \\
\text { nutrition }(\mathrm{PN})\end{array}$ & 1 & 8.33 \\
\hline ALL*** & 3 & 25.00 \\
\hline \multicolumn{3}{|l|}{ Nutritional intervention type } \\
\hline Early PN & 2 & 16.67 \\
\hline Early EN & 1 & 8.33 \\
\hline Early goal-directed nutrition (EGDN) & I & 8.33 \\
\hline
\end{tabular}

(Continued)
Table 2 (Continued).

\begin{tabular}{|l|l|l|}
\hline Characteristic & Number & $\begin{array}{l}\text { Percentage } \\
\text { (\%) }\end{array}$ \\
\hline Early adequate nutrition & $\mathrm{I}$ & 8.33 \\
Higher protein delivery & $\mathrm{I}$ & 8.33 \\
Higher energy delivery & $\mathrm{I}$ & 8.33 \\
Low energy delivery & 2 & 16.67 \\
Energy and protein delivery & $\mathrm{I}$ & 8.33 \\
Intermittent enteral feeding & $\mathrm{I}$ & 8.33 \\
N/A & $\mathrm{I}$ & 8.33 \\
\hline Physical functioning measure(s) & & \\
Function & $12 / I^{\#}$ & $54.55 / 8.33^{\#}$ \\
Muscle strength & $6 / 3^{\$}$ & $27.27 / 50.00^{\$}$ \\
Muscle mass & $4 / I^{\&}$ & $18.18 / 25.00^{\text {\&\& }}$ \\
\hline LOE & & \\
I & 2 & 16.67 \\
II & 6 & 50.00 \\
III & $\mathrm{I}$ & 8.33 \\
VI & 3 & 25.00 \\
\hline
\end{tabular}

Notes: *Descriptive study consists of prospective and retrospective studies. **Mechanically ventilated consists of mechanically ventilated and expected to receive enteral nutrition for at least 2 days/acutely admitted/with sepsis/ with multiorgan failure/for at least 48 hours/ for at least 24 hours. ***ALL means that all ICU patient was qualified to enroll in a study. "Total function outcome measure (n)/total function outcome measure improved (n). ${ }^{\text {"Wtal }}$ Totanction outcome measure $(\%) /$ total function outcome measure improved (\%). ${ }^{\$}$ Total muscle strength outcome measure (n)/total muscle strength outcome measure improved (n). ${ }^{\$}$ Total muscle strength outcome measure (\%)/total muscle strength outcome measure improved (\%). ${ }^{\&}$ Total muscle mass outcome measure (n)/total muscle mass outcome measure improved (n). ${ }^{8 \&}$ Total muscle mass outcome measure (\%)/total muscle mass outcome measure improved (\%).

Abbreviations: N/A, not applicable (systematic reviews/meta-analyses); RCT, randomized control trial; ICU, intensive care unit; LOE, level of evidence.

early EN, early goal-directed nutrition (EGDN), early adequate nutrition, higher protein delivery, higher energy delivery, energy and protein delivery, and intermittent enteral feeding were one $(8.33 \%)$ each. Almost half of the interventions are characterized as early nutrition delivery $(41.67 \%)$. Nearly half concerned with energy and protein delivery $(41.67 \%)$. Details of the interventions are presented in Table 3.

Among the seven intervention trials identified, the energy targets of six were individualized, namely using equations (the Harris-Benedict equation, ${ }^{35}$ the Quark RMR Indirect Calorimeter, ${ }^{36}$ and the modified Penn State Equation ${ }^{37}$ in three trial respectively), indirect calorimetry (around $25 \mathrm{kcal} / \mathrm{kg} / \mathrm{d}(24 \mathrm{kcal} / \mathrm{kg} / \mathrm{d}$ for the higher protein group, $26 \mathrm{kcal} / \mathrm{kg} / \mathrm{d}$ for the lower protein group $){ }^{38} 25-30 \mathrm{kcal} / \mathrm{kg} / \mathrm{d}(25 \mathrm{kcal} / \mathrm{kg} / \mathrm{d} \text { initially })^{39}$ and $1.5 \mathrm{kcal} / \mathrm{kg} / \mathrm{h}^{40}$ ) in three trials respectively, etc. to 


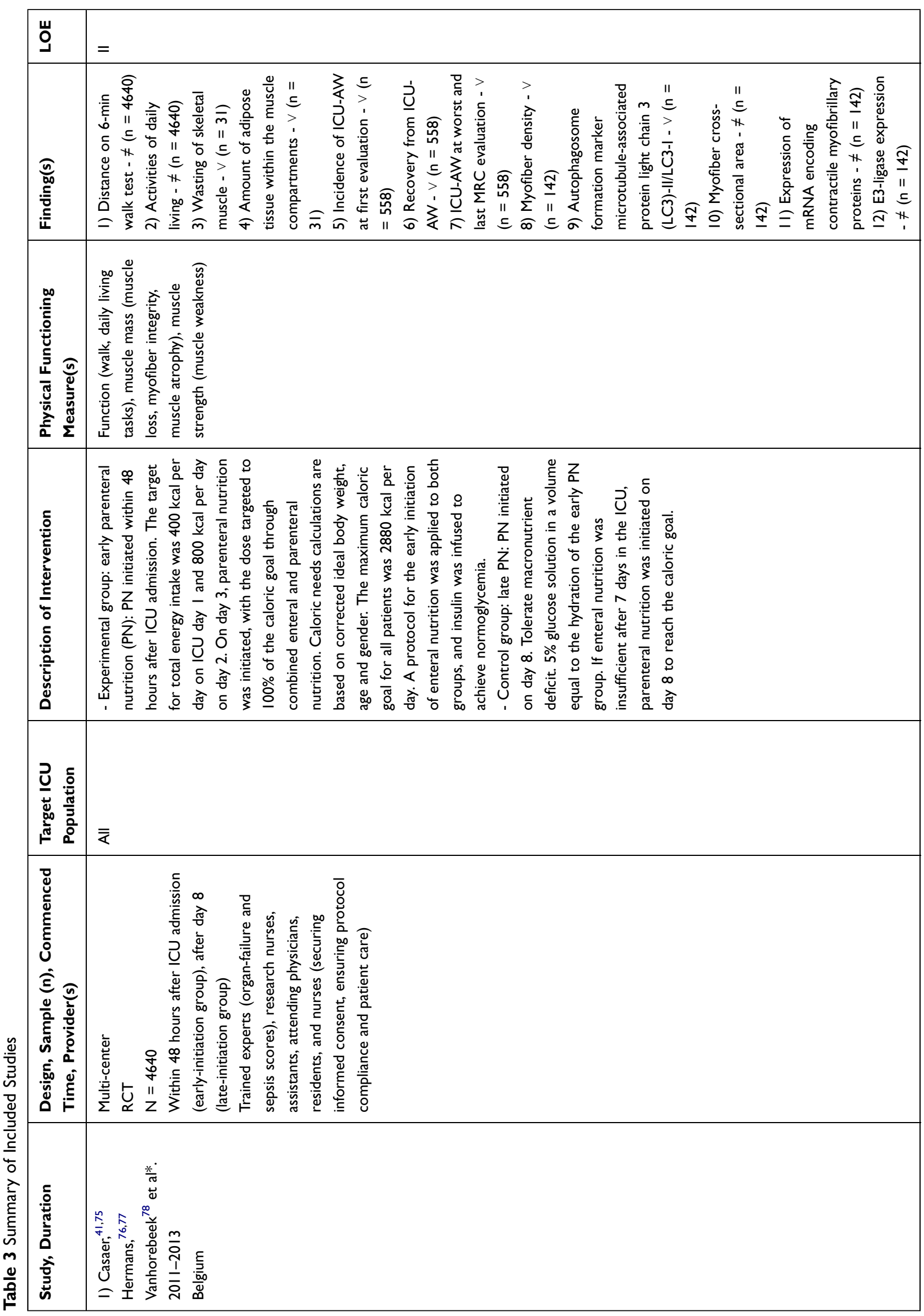




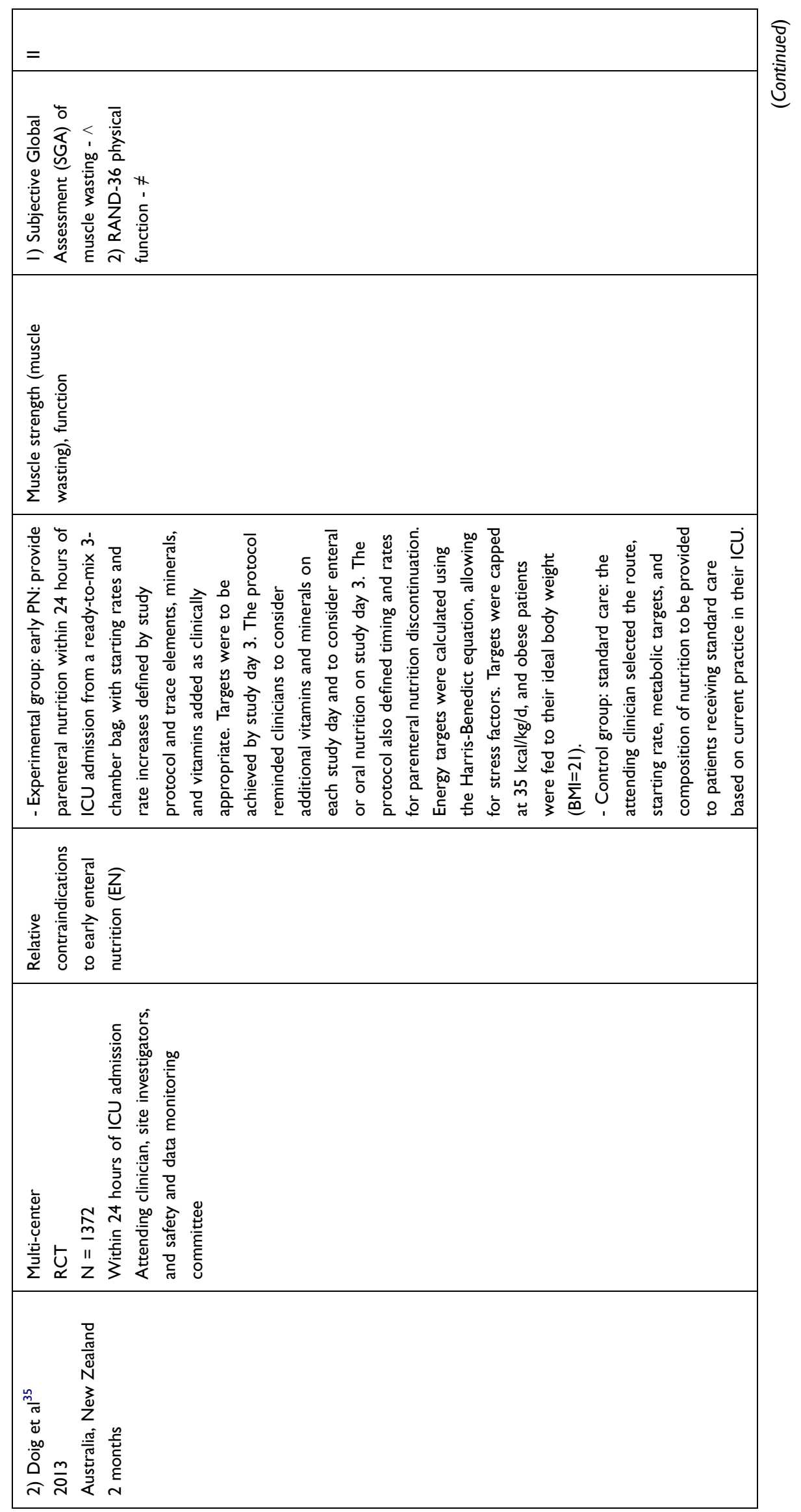




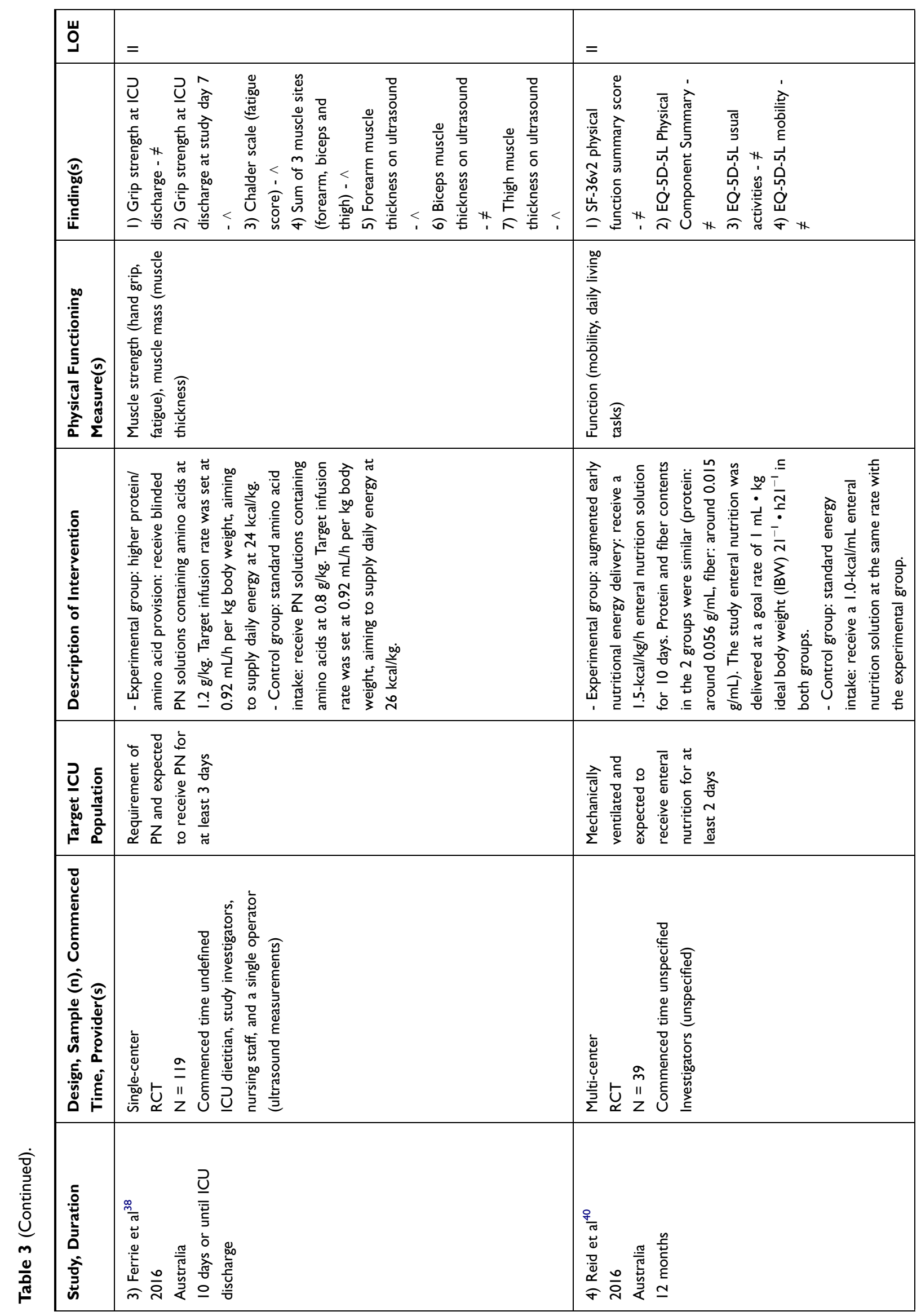




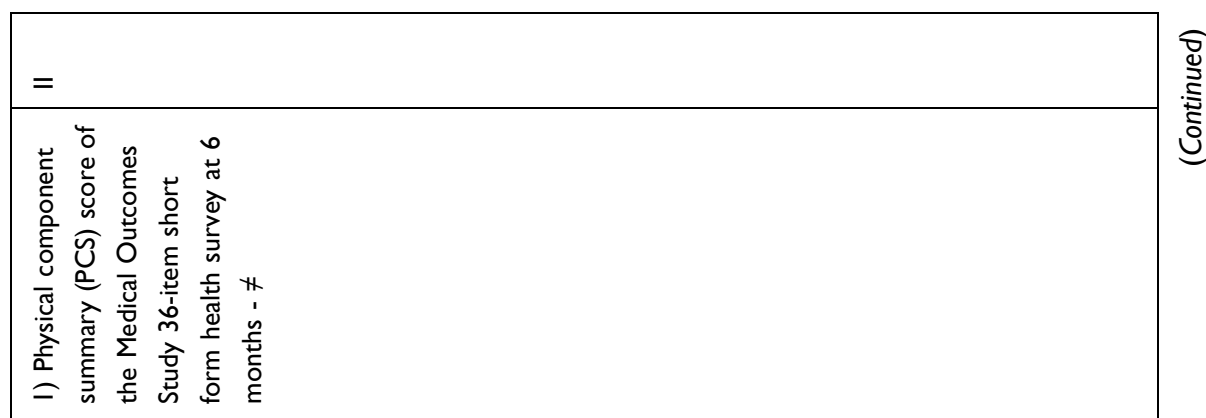

흔
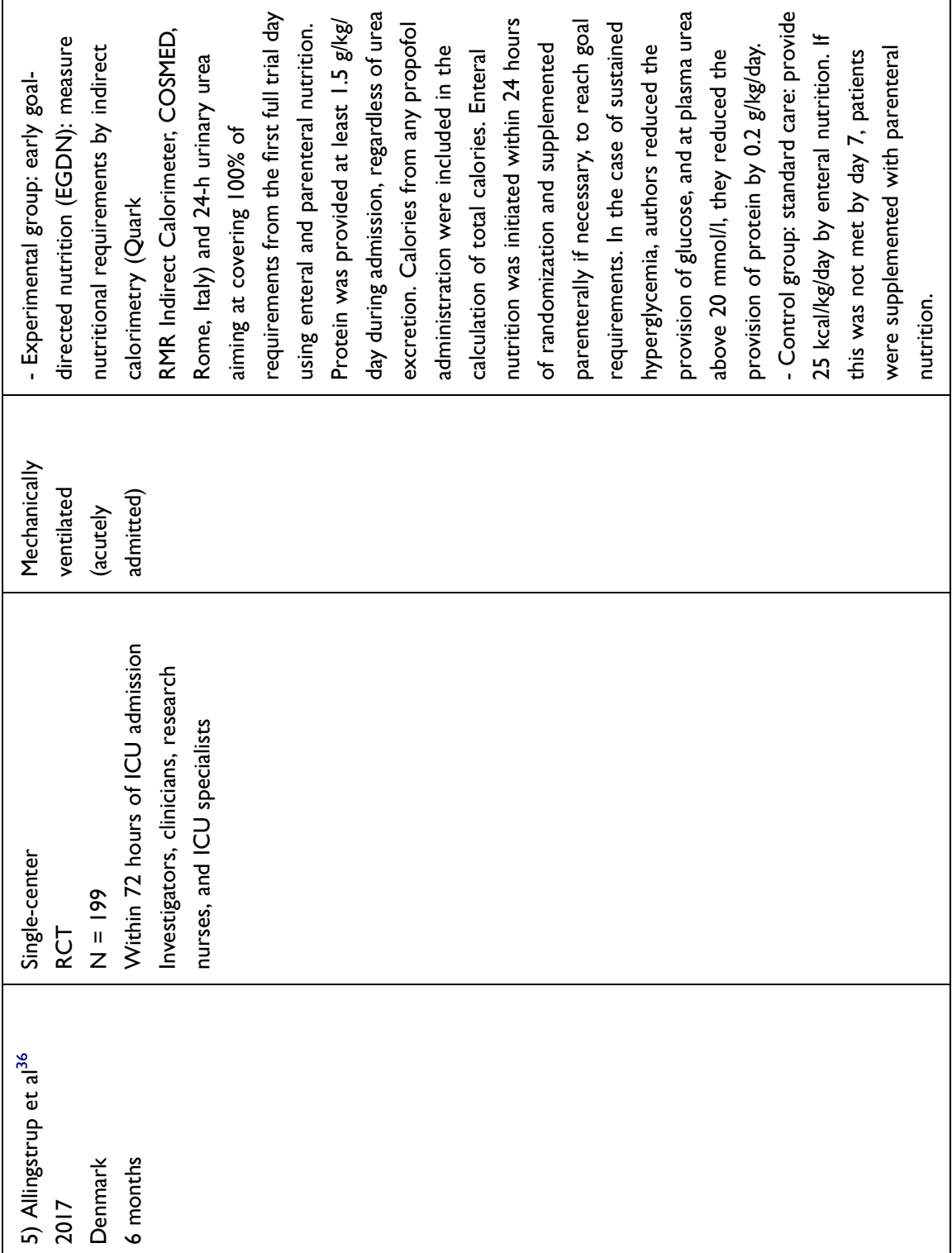


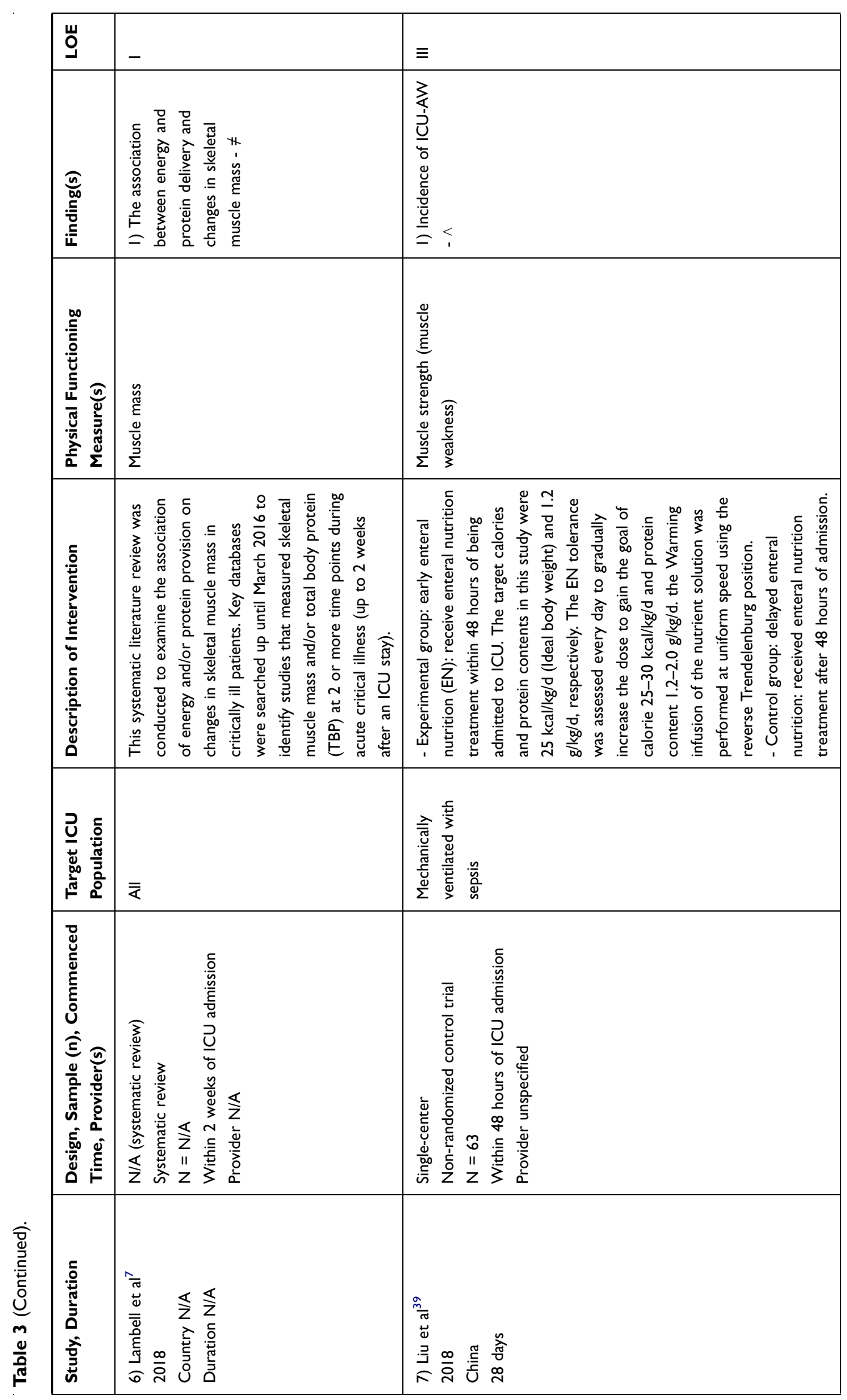




\begin{tabular}{|c|c|c|}
\hline$>$ & - & $>$ \\
\hline 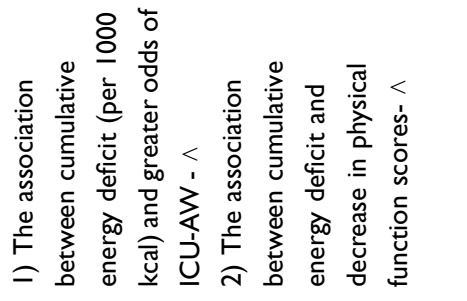 & 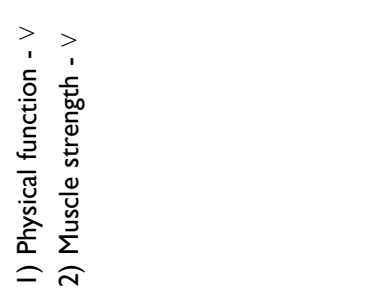 & 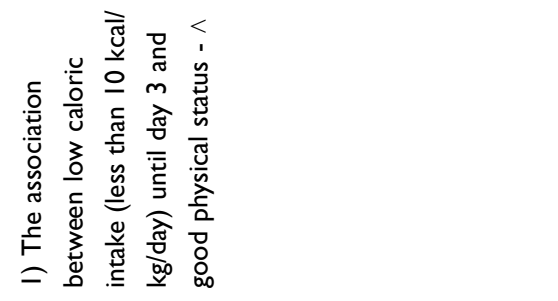 \\
\hline 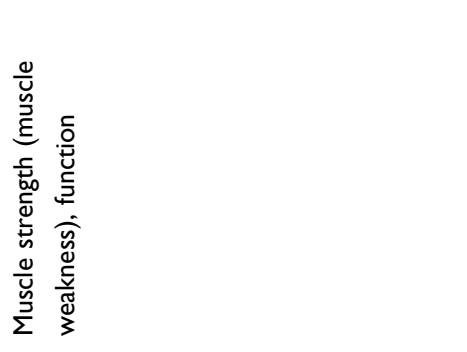 & 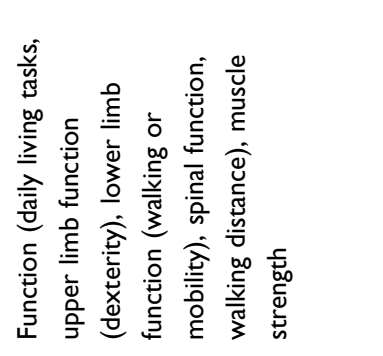 & 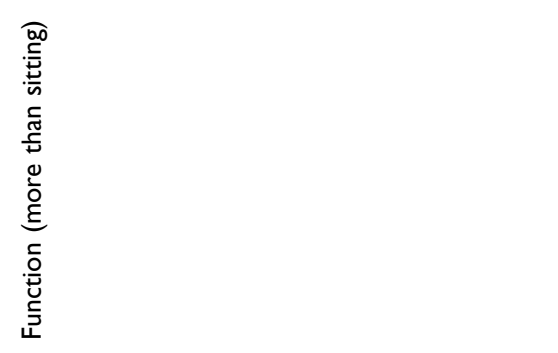 \\
\hline 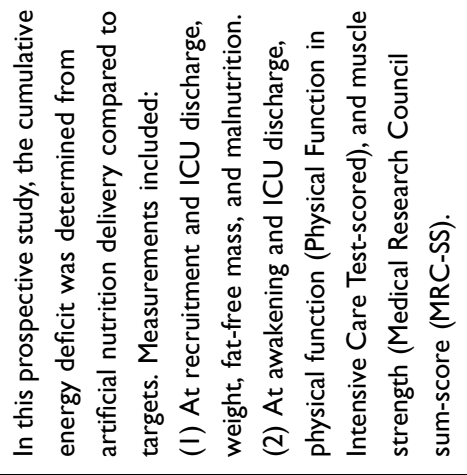 & 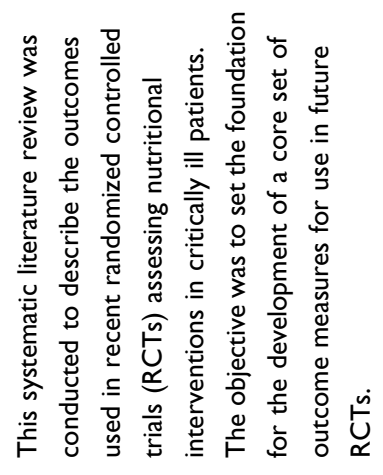 & 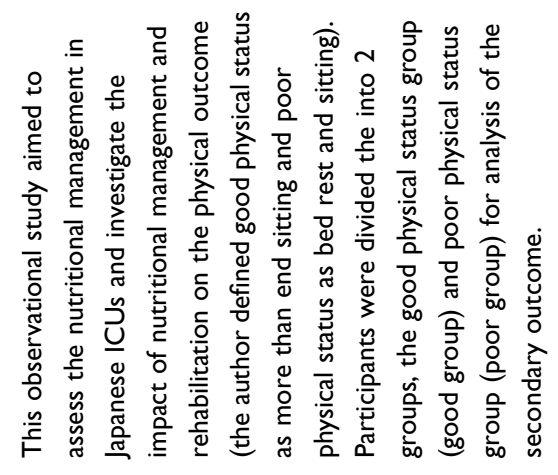 \\
\hline 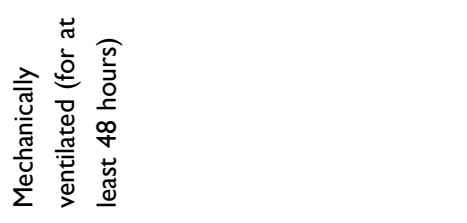 & $\bar{\varangle}$ & 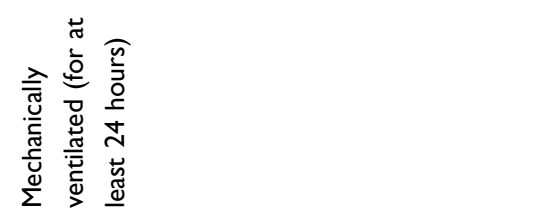 \\
\hline 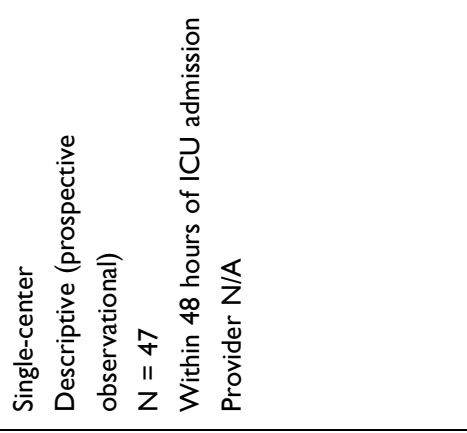 & 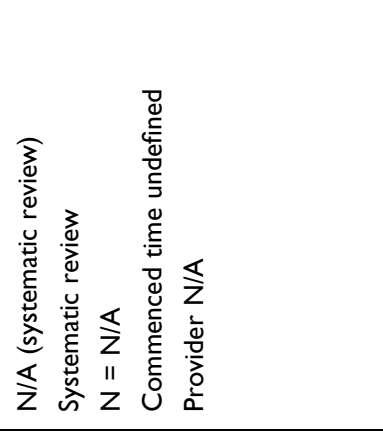 & 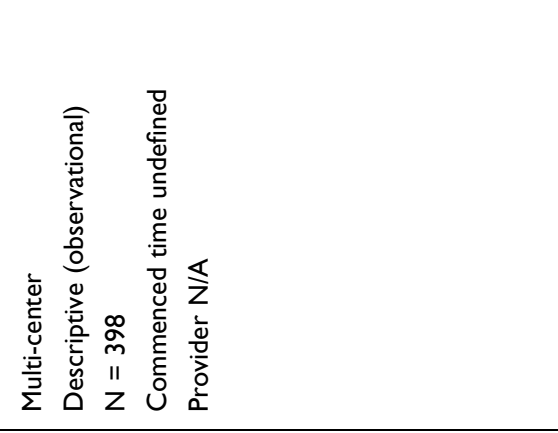 \\
\hline 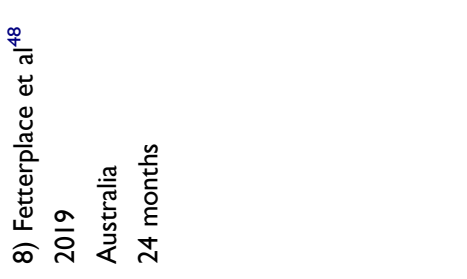 & 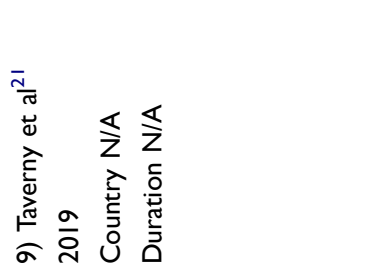 & 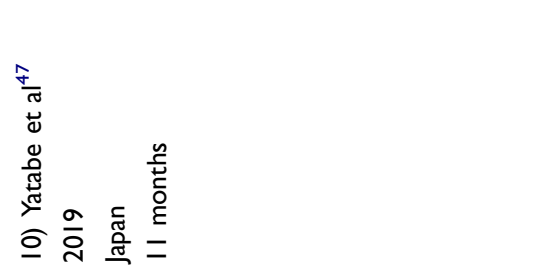 \\
\hline
\end{tabular}




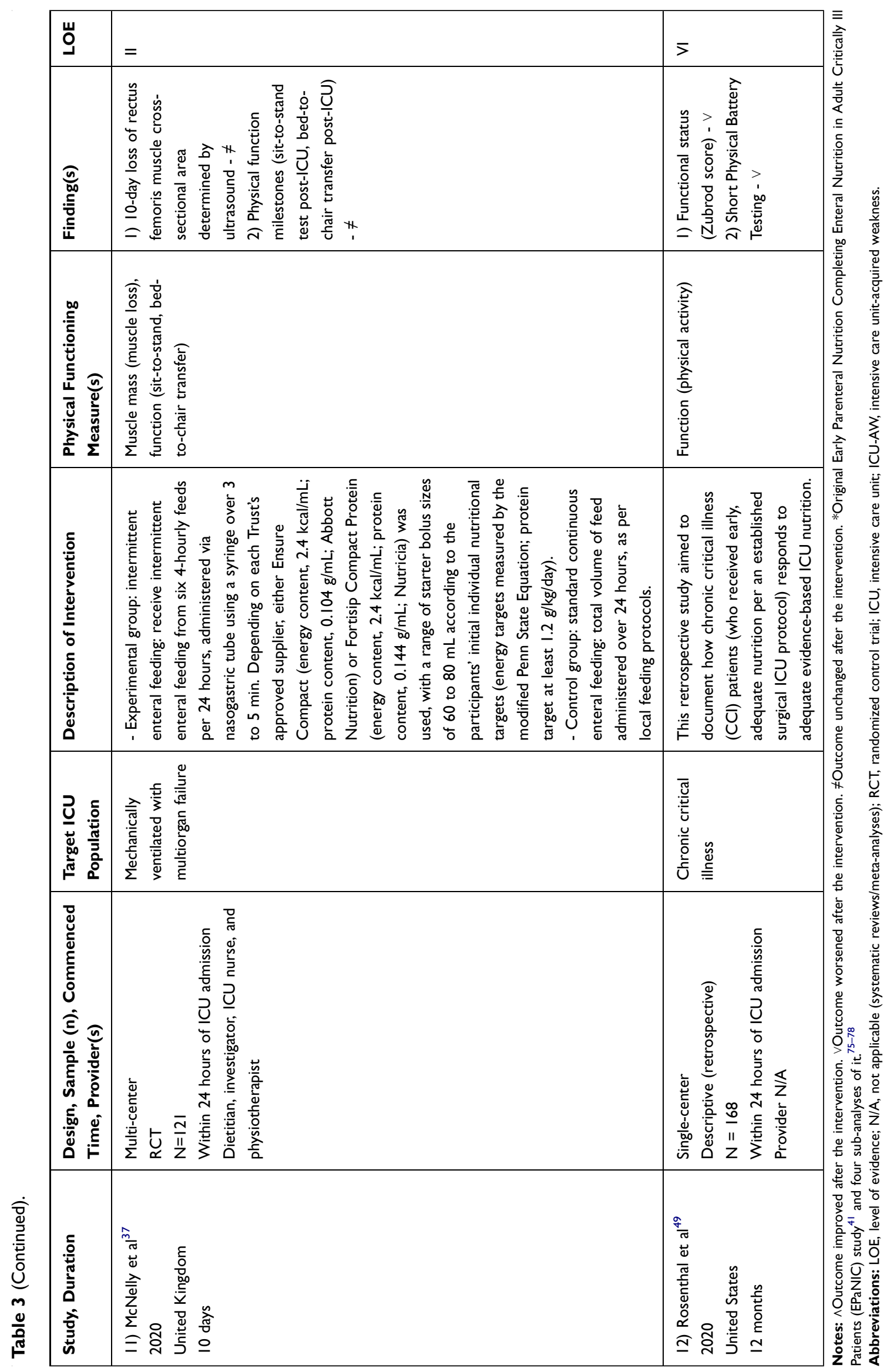


dynamically measure individuals' energy targets. Only one trial ${ }^{41}$ of the seven ones had its energy targets fixed in specific amounts (400 kcal on day 1, $800 \mathrm{kcal}$ on day 2 , and $2880 \mathrm{kcal} / \mathrm{d}$ after day 2).

Four out of the seven intervention trials had individualized protein targets $\left(0.8 \mathrm{~g} / \mathrm{kg}\right.$ or $1.2 \mathrm{~g} / \mathrm{kg},{ }^{38} 1.2-2.0 \mathrm{~g} / \mathrm{kg} / \mathrm{d}$ $\left(1.2 \mathrm{~g} / \mathrm{kg} / \mathrm{d}\right.$ initially), ${ }^{39}$ at least $1.2 \mathrm{~g} / \mathrm{kg},{ }^{37}$ and at least 1.5 $\mathrm{g} / \mathrm{kg}^{36}$ ), which were set based on the patients' weight only. One of the rests of the seven trials had a fixed protein target $(0.056 \mathrm{~g} / \mathrm{mL}){ }^{40}$ The others did not specify their protein delivery targets.

Most of the seven trials (five) were carried out by multidisciplinary teams, of which clinicians and nursing staff were the most common members. Two teams $^{37,38}$ included dietitians, and one $\mathrm{e}^{37}$ of them had a physiotherapist to assess the PF. The above five studies all clarified each team member's corresponding tasks, of which one study by McNelly et $\mathrm{al}^{37}$ demonstrated most clearly by showing a chart of this information. Two ${ }^{39,40}$ of the seven trials specified neither the professions of the research members nor their responsibilities.

Among the seven intervention studies, three $\mathrm{e}^{36,38,41}$ were designed based on well-accepted evidence. The one by Casaer et $\mathrm{al}^{41}$ was based on the guidelines for early initiation of parenteral nutrition, but without mentioning which specific guidelines were utilized. The protein delivery of the trial conducted by Ferrie et $\mathrm{al}^{38}$ was based on the 2006 ESPEN guidelines, ${ }^{42}$ the 2009 ESPEN guidelines, ${ }^{43}$ and the 2009 ASPEN guidelines. ${ }^{44}$ The energy expenditure measurement of the one by Allingstrup et $\mathrm{al}^{36}$ was based on the 2009 ESPEN guidelines, $^{45}$ the 2016 SCCM, and the ASPEN guidelines. $^{46}$

The most common commenced time for included articles was within 24 hours and within 48 hours after ICU admission ( $\mathrm{n}=3,23.08 \%$, both). Within 72 hours after ICU admission was the least $(\mathrm{n}=2,15.38 \%)$, and many were unspecified $(n=3,23.08 \%)$.

\section{Description of Physical Functioning Related Outcome Measures}

Function ( $\mathrm{n}=12,54.55 \%)$, including walk, sitting and daily living tasks, was the primary PF measure, followed by muscle strength $(\mathrm{n}=6,27.27 \%$, consisting of muscle weakness, handgrip, fatigue, etc.) and muscle mass $(n=4$,
$18.18 \%$, consisting of muscle thickness and muscle loss, etc.).

\section{Description of Physical Functioning Related Results \\ Function}

Among the nine studies that studied the influence of nutritional interventions on function, only one multi-centered observational study by Yatabe et $\mathrm{al}^{47}$ found that low caloric intake (less than $10 \mathrm{kcal} / \mathrm{kg} /$ day) until day three was associated with good physical status in mechanically ventilated (for at least 24 hours) patients, which was defined as more than end sitting.

Five studies ${ }^{35-37,40,41}$ found no significant effect on function from nutritional interventions. One prospective observational study ${ }^{48}$ found that cumulative energy deficit was associated with decreased function scores in the mechanically ventilated (for at least 48 hours).

One systematic review ${ }^{21}$ found that nutritional interventions deteriorated ICU patients' function. Similarly, one retrospective study ${ }^{49}$ found that adequate evidencebased ICU nutrition worsened chronic critical illness (CCI) patients' function.

\section{Muscle Strength}

Three studies showed that muscle strength benefited from nutritional interventions, including early $\mathrm{PN}$ in patients with relative contraindications to early $\mathrm{EN},{ }^{35}$ higher protein/amino acid provision in those requiring $\mathrm{PN}^{38}$ early EN in mechanically ventilated patients with sepsis. ${ }^{39}$ One prospective observational study ${ }^{48}$ found that cumulative energy deficit was associated with greater ICU-AW odds in mechanically ventilated patients (for at least 48 hours).

However, the RCT by Casaer et $\mathrm{al}^{41}$ demonstrated that an early PN intervention was detrimental to muscle strength. One systematic review ${ }^{21}$ found that nutritional interventions worsened muscle strength.

\section{Muscle Mass}

Only the one by Ferrie et $\mathrm{al}^{38}$ found nutritional interventions beneficial to muscle mass (sum of 3 muscle sites (forearm, biceps, and thigh), forearm muscle thickness, thigh muscle thickness), but with no significant effect on biceps muscle thickness.

The one by Casaer et $\mathrm{al}^{41}$ found that early EN either worsened muscle mass or have no significant effect on it. One systematic review ${ }^{7}$ found no significant association 
between energy and protein delivery and changes in skeletal muscle mass. One $\mathrm{RCT}^{37}$ found that intermittent enteral feeding did not significantly affect muscle mass in mechanically ventilated patients with multiorgan failure.

\section{Discussion}

To our knowledge, this is the first integrative review to focus exclusively on studies concerned with nutritional interventions on PF for ICU patients. It shows that the related studies over the past decade have been mostly quantitative, of which are primarily multicentered RCTs and have ample sample sizes, allowing them to show the actual effect and generalizability of their interventions and demonstrating a relatively high level of evidence of the studies of this topic. One included systematic review was conducted in 2016 but was published two years later, with the inclusion of only six studies, of which merely two were RCTs, while others were observational ones, which might render the evidence found in this included systematic review inconclusive. We found that most included studies were published in recent five years, suggesting that this realm is a relatively new research hotspot. It is an inevitable trend to explore more about the nutritional interventions on PF in the future to contribute to the form of evidence to deliver nutrition in a way that prevents the deterioration of the PF of critically ill patients. It thus adds to the possibility of a better quality of life after a critical illness. $^{50}$

Given the rapid onset of muscle wasting within hours of $\mathrm{MV},{ }^{50}$ it is imperative to pay close attention to the PFrelated changes of mechanically ventilated ICU patients, which is corresponding with what we found in our review that the majority of the target ICU population is the mechanically ventilated. Nevertheless, as pointed out by Chapple et al, ${ }^{51}$ the number of patients who are either never mechanically ventilated or only ventilated for a short time during their ICU stay is growing, while current nutrition guidelines provide limited recommendations specific for this population. Therefore, the nutritional needs of this population are to be ascertained in future trail designs. As recommended by the ESPEN guideline (2018), ${ }^{22}$ which is one of the most updated nutritional guidelines for the critically ill to date, the nutrition delivery should be commenced within $48 \mathrm{~h}$ of ICU admission, and almost half of the included studies in this review set their commenced time accordingly and have focal considerations of early administration of nutrition. However, one limitation of the guidelines to date is that they concern little to the effects of nutrition on ICU patients' PF. So there is great possibility that the most suitable time to start feeding benefiting PF lies elsewhere (like $17 \mathrm{~h}$ for instance). Therefore, though with studies of high quality in the field in terms of the feeding commenced time (eg, early/late PN/EN), the best commenced time of nutritional intervention on PF still requires further exploration. More large-scale observational studies concerning the starting timeframe are warranted, before the design of experimental studies, to find the possible suitable commenced time in different populations, either the distinct types of ICU population (eg, disease type, mechanically ventilated or not) or the various races of population (eg, country, northern or the southern part of one country). In order to get a knowing of what timeframe is possibly better to start what kind of nutrition for the sake of the patient's PF through observation in the first place, as well as which category of patients might benefit more from certain interventions. Then plan and carry out experimental studies to further pin down the suitable time, nutrition therapy, and the population afterwards.

More than half of the reviewed studies' assessed PF are function, which showed little improvement. This finding, both on the proportion and the result of function, is similar to what has been found in a systematic review by Taverny et al. ${ }^{21}$ One possible reason why almost all function outcomes failed to improve is that this PF outcome is relatively hard to measure in ICU patients than in general wards. For one thing, the needed treatments to the patient's critical illness (eg, sedation, continuous renal replacement therapy (CRRT)) along with the caregivers' fear of causing adverse events (eg, fall, tube peeling) impedes the patient to perform the movements (eg, walking, transfer from bed to chair, using the toilet) needed for measuring his or her function. ${ }^{50,52}$ For another, the critical illness itself, which commonly needs a relatively long time to recover and usually will not be fully healed even when the patient is going to be discharged from ICU, render the muscle strength and activity tolerance of the patient too limited to do the required movements even when it is the time that he or she is ready to get out of ICU. ${ }^{53}$ Besides, even after the critical illness is cured, the function impaired during the disease still requires some time to recover from fulfilling higher movement goals, ${ }^{54}$ of which the degree of difficulty is much greater than their last achieved ones, take, for example, the Barthel Index which is common in function assessment of ICU patients, ${ }^{55,56}$ from lying in bed 
incapable of walking to propelling a wheelchair independently at least 50 yards. ${ }^{55}$

Among the six muscle strength outcomes measured, half were improved by nutritional interventions, and most muscle strength outcomes were muscle weakness primarily assessed by the Medical Research Council sum score (MRC-SS), which is commonly used for the detection of ICU-AW. ${ }^{57}$ This satisfying improvement is probably due to the relative easiness for the critically ill patient to perform the movements (eg, wrist extension, elbow flexion, knee extension) required for assessing muscle strength in contrast to the assessment of function since the patient do not have to get out of bed to do these movements. ${ }^{58}$ Furthermore, achieving a higher goal in terms of muscle strength (eg, from resisting partial force to resisting full force when extending the wrist) is less demanding than that of function.

In terms of the measurement of energy target/energy expenditure (EE), around half of the included interventional trials applied predictive equations, and about half adopted indirect calorimetry. Indirect calorimetry is preferred over predictive equations in most updated critical nutrition guidelines (A.S.P.E.N. $(2016)^{24}$ and ESPEN $(2018)^{22}$ ), due to the significant inaccuracy (up to $60 \%$ ) of predictive equations as a result of the difficulty of assessing body weight accurately. ${ }^{22,59}$ In the absence of indirect calorimetry, oxygen consumption $\left(\mathrm{VO}_{2}\right)$ from pulmonary arterial catheter or carbon dioxide production $\left(\mathrm{VCO}_{2}\right)$ from the ventilator can be more accurate on the evaluation of $\mathrm{EE}$ than predictive equations, though less than indirect calorimetry. ${ }^{22}$ If indirect calorimetry, VO 2 or VCO 2 measurements are all unavailable, simple weight-based equations (eg, 20-25 kcal $/ \mathrm{kg} / \mathrm{d}$ ) may be preferred. $^{22}$

Two out of seven intervention studies did not specify their protein delivery when their intervention is mainly on energy delivery. Two out of seven intervention studies did not specify what discipline the persons made up of their research team and what responsibility each member took. Despite the relatively small proportion these studies account for, it is worth noting that researchers should provide a detailed report of the provision of energy and protein, as well as the details of the constituent disciplines of the team members and their respective responsibilities in their research since transparency on these details, will promote the uptake of research evidence into practice. ${ }^{60-62}$ Otherwise, questions such as "How much protein/energy should we deliver to our patients?" and "Which discipline of personnel should we include in our research team and what kind of task he or she should shoulder?" will be challenging to answer and therefore hamper both the design and the replication of the intervention.

However, what is uncertain is if the researchers reflect that their interventions are founded on principles of specific guidelines. Only $28.57 \%$ of the intervention studies stated their theoretical base clearly, which limits understanding of nutritional interventions on PF in ICU patients within a broader context, including the significant transition of interventions into practice. ${ }^{63,64}$

\section{Implications for Future Research}

Future nutritional interventions on PF in ICU patients are especially encouraged to incorporate the following details. Firstly, the intervention should be based on well-accepted evidence, which should be specified in the report to guarantee the research's rationality and provide further guidance in the implementation process. Moreover, every delivered nutrition ingredient's details are to be explicated even if only one component is the primary intervention to promote the intervention's generalization. Also, the disciplines of the research members and their respective tasks should be stated clearly. The addition of muscle strengthrelated measures (ICU-AW especially) can also be considered since this $\mathrm{PF}$ is more possible to be performed within the ICU setting.

As mentioned above, more large-scale observational studies concerning the starting timeframe are required to find the possible suitable commenced time of feedings in different populations, facilitating the further design of experimental studies.

Besides, it is pointed out by a research that the optimal nutritional management among ICU patients with lower body mass index (BMI) remains unclear, ${ }^{47}$ calling for more researches in terms of this population since it will benefit most Asian population and lean Western and Oceanian population. Additionally, the nutritional management of ICU patients who are not mechanically ventilated or only ventilated for a short period requires further exploration. $^{51}$

Most included studies adopted quantitative approaches in investigating nutritional interventions on PF in ICU patients, but almost all failed to take the feeling and experience of the patients and/or their caregivers into account, so were the qualitive ones, not in line with the wholistic health concept advocated by the World Health Organization (WHO). ${ }^{65}$ As suggested in a study, patients might be 
burdened by the nutritional treatment both during hospitalization and after discharge. ${ }^{66}$ Considering that qualitative research could contribute to practical intervention delivery insights, this review highlights the need for more qualitative studies investigating the perspectives of the patients and/or their caregivers, in an effort to treat the person as a whole. Current qualitative studies have investigated the association between nutrition and the PF of ICU patients in either a nation (ie, Japan) ${ }^{47}$ or certain types of ICU patients (ie, chronic critical illness patients). ${ }^{49}$ However, depth interviews are needed to provide more insight into the patients' own experience of having certain types of nutrition delivery and especially on their PF in or out of ICU, as well as their caregivers' (medical staffs, family members) perspectives and experience when taking care of them, which is practically ignored in the current studies. Nutritional interventions on PF in the critically ill could then be optimized and improve the patients' outcomes, and meanwhile, taking into account the patients' and the caregivers' feeling and experience rather than focus merely on the symptoms. Moreover, it is suggested that the incorporation of co-design including both clinicians/researchers and patients should be adopted in the trial design of nutritional interventions on the critically ill, ${ }^{51,67}$ which is likely to benefit from the investigation of patients'/caregivers' insights. Theories about wholistic health could be applied in various types of research studies concerning this topic.

Apart from nutritional interventions solely, it is recommended that bundled or synergistic therapies should be taken into consideration, ${ }^{51}$ such as combined nutritional and physical interventions, as this enhanced synergistic treatment may increase muscle mass, and improve activities of daily living within a short period after discharge for ICU patients. ${ }^{66}$

Furthermore, our results can be used as a guideline for design of the research and practice related to nutritional interventions on the critically ill's PF, such as the energy/ protein target, patient populations, PF, etc.

\section{Limitations}

First of all, it is essential to highlight that only a minimal number of sources were identified for inclusion, a challenging factor for conducting a systematic review or metaanalysis and drawing clear conclusions from the evidence. However, the aim of this review is to summarize the details of the researches concerning the nutritional intervention on functioning of critically ill patients, promoting a more comprehensive understanding of this topic, in order to provide references for future studies, instead of paying more attention to the level of evidence of the current researches and pinning down the effects of this type of intervention like in the case of systematic reviews. ${ }^{68,69}$ Moreover, compared to scoping reviews, which aim to identify and mapping certain characteristics or concepts of studies as well as analyze the knowledge gaps, ${ }^{70,71}$ the integrative review design, focusing on using diverse data sources to develop holistic understanding of the topic of interest, ${ }^{72}$ suits our aim best. In addition, even though muscle mass, muscle strength, and function, constituting the PF analyzed in this review, share a common background, mechanisms leading to their impairments are not similar. So we analyzed these outcomes separately to make up for this shortcoming. Besides, protocols and pilot studies were excluded in this review, considering the former's lack of results and the latter's flimsy evidence. However, this review included both primary and secondary studies with a range of objectives, as well as various research types (quantitative studies, qualitative studies and systematic reviews/meta-analyses), and thus it offers broad coverage of literature in this area.

\section{Conclusions}

This review demonstrates that research on nutritional interventions on critically ill patients' $\mathrm{PF}$ is limited in number, but most of these are large-scale RCTs of a high level of evidence. However, though of high quality, there are still gaps to be filled in this field. Firstly, few intervention studies specified their evidence basis. Qualitative studies are warranted to further investigate the timeframe of feeding commencement in the best interest of PF. Additionally, the management of ICU patients with lower BMI lacks evidence of this topic. Moreover, the existing research highlights a need for more studies to the wholistic health of the related patients, especially qualitative studies, looking into the perspectives of the patients themselves and their medical caregivers as well as their families during or after the provision of certain types of nutrition to the patients, to advance research and to trigger a further discussion on this topic.

\section{Funding}

This study is supported by the National Natural Science Foundation of China (71704040). The funders had no role in study design, decision for publication and preparation of the manuscript. 


\section{Disclosure}

The authors report no conflicts of interest for this work.

\section{References}

1. González-Seguel F, Corner EJ, Merino-Osorio C. International classification of functioning, disability, and health domains of 60 physical functioning measurement instruments used during the adult intensive care unit stay: a scoping review. Phys Ther. 2019;99(5):627-640. doi:10.1093/ptj/pzy158

2. Witteveen E, Wieske L, Sommers J, et al. Early prediction of intensive care unit-acquired weakness: a Multicenter External Validation Study. J Intensive Care Med. 2020;35(6):595-605. doi:10.1177/ 0885066618771001

3. Vanhorebeek I, Latronico N, Van den Berghe G. ICU-acquired weakness. Intensive Care Med. 2020;46(4):637-653. doi:10.1007/s00134020-05944-4

4. Zhang L, Hu W, Cai Z, et al. Early mobilization of critically ill patients in the intensive care unit: a systematic review and metaanalysis. PLoS One. 2019;14(10):e223185. doi:10.1371/journal. pone. 0223185

5. Ndahimana D, Kim E. Energy requirements in critically ill patients. Clin Nutr Res. 2018;7(2):81-90. doi:10.7762/cnr.2018.7.2.81

6. Puthucheary Z, Rawal J, McPhail M, et al. Acute skeletal muscle wasting in critical illness. JAMA. 2013;310(15):1591-1600. doi:10.1001/jama.2013.278481

7. Lambell KJ, King SJ, Forsyth AK, et al. Association of energy and protein delivery on skeletal muscle mass changes in critically ill adults: a systematic review. J Parenter Enteral Nutr. 2018;42 (7):1112-1122. doi:10.1002/jpen.1151

8. Ju S, Choi SM, Park YS, et al. Rapid muscle loss negatively impacts survival in critically ill patients with cirrhosis. J Intensive Care Med. 2020;35(7):663-671. doi:10.1177/0885066618775706

9. Nedergaard H, Haberlandt T, Reichmann P, et al. Patients' opinions on outcomes following critical illness. Acta Anaesthesiol Scand. 2018;62(4):531-539. doi:10.1111/aas.13058

10. Dos Santos C, Hussain SNA, Mathur S, et al. Mechanisms of chronic muscle wasting and dysfunction after an intensive care unit stay. $\mathrm{Am}$ J Respir Crit Care Med. 2016;194(7):821-830. doi:10.1164/ recm.201512-2344OC

11. Pedersen B, Febbraio M. Muscles, exercise and obesity: skeletal muscle as a secretory organ. Nat Rev Endocrinol. 2012;8(8):457465. doi:10.1038/nrendo.2012.49

12. Sherwood L. Human Physiology: From Cells to Systems. Pacific Grove, CA: Brooks/Cole; 2001:240.

13. Herridge M. Textbook of Post-ICU Medicine: The Legacy of Critical Care. Introduction: Life After the ICU. Oxford University Press; 2014.

14. Cherry-Bukowiec JR. Optimizing nutrition therapy to enhance mobility in critically ill patients. Crit Care Nurs Q. 2013;36(1):28-36. doi:10.1097/CNQ.0b013e31827507d7

15. Gostyńska A, Stawny M, Dettlaff K, et al. Clinical nutrition of critically ill patients in the context of the latest ESPEN guidelines. Medicina. 2019;55(12):12. doi:10.3390/medicina55120770

16. Wei X, Day AG, Ouellette-Kuntz H, et al. The association between nutritional adequacy and long-term outcomes in critically ill patients requiring prolonged mechanical ventilation: a Multicenter Cohort Study. Crit Care Med. 2015;43(8):1569-1579. doi:10.1097/ CCM.0000000000001000

17. Heyland D, Stephens K, Day A, et al. The success of enteral nutrition and ICU-acquired infections: a multicenter observational study. Clin Nutr. 2011;30(2):148-155. doi:10.1016/j.clnu.2010.09.011

18. Heyland D, Cahill N, Day A. Optimal amount of calories for critically ill patients: depends on how you slice the cake! Crit Care Med. 2011;39(12):2619-2626. doi:10.1097/CCM.0b013e318226641d
19. Alberda C, Gramlich L, Jones N, et al. The relationship between nutritional intake and clinical outcomes in critically ill patients: results of an international multicenter observational study. Intensive Care Med. 2009;35(10):1728-1737. doi:10.1007/s00134-009-1567-4

20. Mooi NM, Ncama BP. Evidence on nutritional therapy practice guidelines and implementation in adult critically ill patients: a scoping review protocol. Syst Rev. 2019;8(1):291. doi:10.1186/s13643019-1194-2

21. Taverny G, Lescot T, Pardo E, et al. Outcomes used in randomised controlled trials of nutrition in the critically ill: a systematic review. Crit Care. 2019;23(1):12. doi:10.1186/s13054-018-2303-7

22. Singer P, Blaser AR, Berger MM, et al. ESPEN guideline on clinical nutrition in the intensive care unit. Clin Nutr. 2019;38(1):48-79.

23. Reintam blaser A, Starkopf J, Alhazzani W, et al. Early enteral nutrition in critically ill patients: ESICM clinical practice guidelines. Intensive Care Med. 2017;43(3):380-398. doi:10.1007/s00134-0164665-0

24. Taylor BE, McClave SA, Martindale RG, et al. Guidelines for the provision and assessment of nutrition support therapy in the adult critically ill patient: Society of Critical Care Medicine (SCCM) and American Society for Parenteral and Enteral Nutrition (A.S.P.E.N.). Crit Care Med. 2016;44(2):390-438.

25. van Lieshout R, Tick LW, de Laat D, et al. Adherence to guidelines on nutrition support during intensive treatment of acute myeloid leukemia patients: a nationwide comparison. Clin Nutr ESPEN. 2020;39:242-250. doi:10.1016/j.clnesp.2020.05.003

26. Arabi YM, Casaer MP, Chapman M, et al. The intensive care medicine research agenda in nutrition and metabolism. Intensive Care Med. 2017;43(9):1239-1256. doi:10.1007/s00134-017-4711-6

27. Machado LDS, Rizzi P, Silva FM. Administration of enteral nutrition in the prone position, gastric residual volume and other clinical outcomes in critically ill patients: a systematic review. Rev Bras Ter Intensiva. 2020;32(1):133-142. doi:10.5935/0103-507X.20200019

28. Luo Y, Qian Y. Effect of combined parenteral and enteral nutrition for patients with a critical illness: a meta-analysis of randomized controlled trials. Medicine. 2020;99(3):e18778. doi:10.1097/MD.0000 000000018778

29. Asrani VM, Brown A, Bissett I, et al. Impact of intravenous fluids and enteral nutrition on the severity of gastrointestinal dysfunction: a systematic review and meta-analysis. J Crit Care Med. 2020;6(1):524. doi:10.2478/jccm-2020-0009

30. Whittemore R, Knafl K. The integrative review: updated methodology. J Adv Nurs. 2005;52(5):546-553. doi:10.1111/j.1365-2648.2005. 03621.x

31. Liberati A, Altman D, Tetzlaff J, et al. The PRISMA statement for reporting systematic reviews and meta-analyses of studies that evaluate health care interventions: explanation and elaboration. PLoS Med. 2009;6(7):e1000100. doi:10.1371/journal.pmed.1000100

32. World Health O. International Classification of Functioning, Disability and Health: ICF. Geneva: World Health Organization; 2001.

33. Parry SM, Granger CL, Berney S, et al. Assessment of impairment and activity limitations in the critically ill: a systematic review of measurement instruments and their clinimetric properties. Intensive Care Med. 2015;41(5):744-762. doi:10.1007/s00134-015-3672-x

34. Melnyk B, Fineout-Overholt E. Evidence-Based Practice in Nursing \& Healthcare: A Guide to Best Practice. 3rd ed. Philadelphia, PA: Wolters Kluwer; 2015.

35. Doig GS, Simpson F, Sweetman EA, et al. Early parenteral nutrition in critically ill patients with short-term relative contraindications to early enteral nutrition: a randomized controlled trial. JAMA. 2013;309(20):2130-2138. doi:10.1001/jama.2013.5124

36. Allingstrup MJ, Kondrup J, Wiis J, et al. Early goal-directed nutrition versus standard of care in adult intensive care patients: the singlecentre, randomised, outcome assessor-blinded EAT-ICU trial. Intensive Care Med. 2017;43(11):1637-1647. doi:10.1007/s00134017-4880-3 
37. McNelly AS, Bear DE, Connolly BA, et al. Effect of intermittent or continuous feed on muscle wasting in critical illness: a Phase II clinical trial. Chest. 2020;158(1):183-194. doi:10.1016/j.chest.20 20.03.045

38. Ferrie S, Allman-Farinelli M, Daley M, et al. Protein requirements in the critically ill: a randomized controlled trial using parenteral nutrition. J Parenter Enteral Nutr. 2016;40(6):795-805. doi:10.1177/ 0148607115618449

39. Liu Y, Zhao W, Chen W, et al. Effects of early enteral nutrition on immune function and prognosis of patients with sepsis on mechanical ventilation. $J$ Intensive Care Med. 2018;35(10):1053-1061. doi: $10.1177 / 0885066618809893$

40. Reid DB, Chapple LS, O'Connor SN, et al. The effect of augmenting early nutritional energy delivery on quality of life and employment status one year after ICU admission. Anaesth Intensive Care. 2016;44 (3):406-412. doi:10.1177/0310057X1604400309

41. Casaer MP, Mesotten D, Hermans G, et al. Early versus late parenteral nutrition in critically ill adults. $N$ Engl J Med. 2011;365(6):506517. doi:10.1056/NEJMoa1102662

42. Volkert D, Berner YN, Berry E, et al. ESPEN guidelines on enteral nutrition: geriatrics. Clin Nutr. 2006;25(2):330-360. doi:10.1016/j. clnu.2006.01.012

43. Bozzetti F, Forbes A. The ESPEN clinical practice guidelines on parenteral nutrition: present status and perspectives for future research. Clin Nutr. 2009;28(4):359-364. doi:10.1016/j.clnu.2009.05.010

44. McClave SA, Martindale RG, Vanek VW, et al. Guidelines for the provision and assessment of nutrition support therapy in the adult critically ill patient: Society of Critical Care Medicine (SCCM) and American Society for Parenteral and Enteral Nutrition (A.S.P.E.N.). J Parenter Enteral Nutr. 2009;33(3):277-316. doi:10.1177/0148607109335234

45. Singer P, Berger MM, Van den Berghe G, et al. ESPEN guidelines on parenteral nutrition: intensive care. Clin Nutr. 2009;28(4):387-400. doi:10.1016/j.clnu.2009.04.024

46. McClave SA, Taylor BE, Martindale RG, et al. Guidelines for the provision and assessment of nutrition support therapy in the adult critically ill patient: Society of Critical Care Medicine (SCCM) and American Society for Parenteral and Enteral Nutrition (A.S.P.E.N.). $J$ Parenter Enteral Nutr. 2016;40(2):159-211. doi:10.1177/0148607 115621863

47. Yatabe T, Egi M, Sakaguchi M, et al. Influence of nutritional management and rehabilitation on physical outcome in Japanese intensive care unit patients: a multicenter observational study. Ann Nutr Metab. 2019;74(1):35-43. doi:10.1159/000495213

48. Fetterplace K, Beach LJ, MacIsaac C, et al. Associations between nutritional energy delivery, bioimpedance spectroscopy and functional outcomes in survivors of critical illness. J Hum Nutr Diet. 2019;32(6):702-712. doi:10.1111/jhn.12659

49. Rosenthal MD, Bala T, Wang ZK, et al. Chronic critical illness patients fail to respond to current evidence-based intensive care nutrition secondarily to persistent inflammation, immunosuppression, and catabolic syndrome. J Parenter Enteral Nutr. 2020;44(7):12371249. doi:10.1002/jpen.1794

50. Clarissa C, Salisbury L, Rodgers S, et al. Early mobilisation in mechanically ventilated patients: a systematic integrative review of definitions and activities. J Intensive Care. 2019;7(1):3. doi:10.1186/ s40560-018-0355-z

51. Chapple L-AS, Ridley EJ, Chapman MJ. Trial design in critical care nutrition: the past, present and future. Nutrients. 2020;12(12):12. doi:10.3390/nu12123694

52. Brock C, Marzano V, Green M, et al. Defining new barriers to mobilisation in a highly active intensive care unit - have we found the ceiling? An observational study. Heart Lung. 2018;47(4):380385. doi:10.1016/j.hrtlng.2018.04.004

53. Zhou W, Shi B, Fan Y, et al. Effect of early activity combined with early nutrition on acquired weakness in ICU patients. Medicine. 2020;99(29):e21282. doi:10.1097/MD.0000000000021282
54. Meyer-Frießem CH, Malewicz NM, Rath S, et al. Incidence, time course and influence on quality of life of intensive care unit-acquired weakness symptoms in long-term intensive care survivors. J Intensive Care Med. 2020:885066620949178. doi:10.1177/0885066620949178

55. Mahoney FI, Barthel DW. Functional evaluation: the barthel index. Md State Med J. 1965;14:61-65.

56. Yi Y, Ding L, Wen H, et al. Is barthel index suitable for assessing activities of daily living in patients with dementia? Front Psychiatry. 2020;11:282. doi:10.3389/fpsyt.2020.00282

57. Mitobe Y, Morishita S, Ohashi K, et al. Skeletal muscle index at intensive care unit admission is a predictor of intensive care unitacquired weakness in patients with sepsis. J Clin Med Res. 2019;11 (12):834-841. doi:10.14740/jocmr4027

58. Hermans G, Clerckx B, Vanhullebusch T, et al. Interobserver agreement of medical research council sum-score and handgrip strength in the intensive care unit. Muscle Nerve. 2012;45(1):18-25. doi:10. $1002 /$ mus. 22219

59. Zusman O, Kagan I, Bendavid I, et al. Predictive equations versus measured energy expenditure by indirect calorimetry: a retrospective validation. Clin Nutr. 2019;38(3):1206-1210. doi:10.1016/j.clnu.20 18.04.020

60. Craig P, Dieppe P, Macintyre S, et al. Developing and evaluating complex interventions: the new medical research council guidance. Int $J$ Nurs Stud. 2013;50(5):587-592. doi:10.1016/j.ijnurstu.2012.09.010

61. Sacks D, Baxter B, Campbell BCV, et al. Multisociety consensus quality improvement revised consensus statement for endovascular therapy of acute ischemic stroke. Int J Stroke. 2018;13(6):612-632. doi:10.1177/1747493018778713

62. Vandenbroucke JP, von Elm E, Altman DG, et al. Strengthening the Reporting of Observational Studies in Epidemiology (STROBE): explanation and elaboration. Int J Surg. 2014;12(12):1500-1524. doi:10.1016/j.ijsu.2014.07.014

63. Davidoff F, Dixon-Woods M, Leviton L, et al. Demystifying theory and its use in improvement. BMJ Qual Saf. 2015;24(3):228-238. doi:10.1136/bmjqs-2014-003627

64. Bradbury-Jones C, Taylor J, Herber O. How theory is used and articulated in qualitative research: development of a new typology. Soc Sci Med. 2014;120:135-141. doi:10.1016/j.socscimed.2014. 09.014

65. Larson JS. The World Health Organization's definition of health: social versus spiritual health. Soc Indic Res. 1996;38(2):181-192. doi:10.1007/BF00300458

66. Kou K, Momosaki R, Miyazaki S, et al. Impact of nutrition therapy and rehabilitation on acute and critical illness: a systematic review. $J$ UOEH. 2019;41(3):303-315. doi:10.7888/juoeh.41.303

67. Haines KJ, Holdsworth C, Cranwell K, et al. Development of a peer support model using experience-based co-design to improve critical care recovery. Crit Care Explor. 2019;1(3):e0006. doi:10.1097/ CCE.0000000000000006

68. Greenhalgh T. Papers that summarise other papers (systematic reviews and meta-analyses). BMJ. 1997;315(7109):672-675. doi:10.1136/bmj.315.7109.672

69. Kirkevold M. Integrative nursing research-an important strategy to further the development of nursing science and nursing practice. $J$ Adv Nurs. 1997;25(5):977-984. doi:10.1046/j.1365-2648.1997.1997 025977.x

70. Colquhoun HL, Levac D, O'Brien KK, et al. Scoping reviews: time for clarity in definition, methods, and reporting. J Clin Epidemiol. 2014;67(12):1291-1294. doi:10.1016/j.jclinepi.2014.03.013

71. Munn Z, Peters MDJ, Stern C, et al. Systematic review or scoping review? Guidance for authors when choosing between a systematic or scoping review approach. BMC Med Res Methodol. 2018;18(1):143. doi:10.1186/s12874-018-0611-x

72. Da Silva RN, Brandão MAG, Ferreira MA. Integrative review as a method to generate or to test nursing theory. Nurs Sci Q. 2020;33 (3):258-263. doi:10.1177/0894318420920602 
73. Heyland DK, Stapleton RD, Mourtzakis M, et al. Combining nutrition and exercise to optimize survival and recovery from critical illness: conceptual and methodological issues. Clin Nutr. 2016;35 (5):1196-1206. doi:10.1016/j.clnu.2015.07.003

74. Hermans G, De Jonghe B, Bruyninckx F, et al. Interventions for preventing critical illness polyneuropathy and critical illness myopathy. Cochrane Database Syst Rev. 2014;2014(1):Cd006832.

75. Casaer MP, Langouche L, Coudyzer W, et al. Impact of early parenteral nutrition on muscle and adipose tissue compartments during critical illness. Crit Care Med. 2013;41(10):2298-2309. doi:10.1097/ CCM.0b013e31828cef02
76. Hermans G, Clerckx B, Vanhullebusch T, et al. Withholding parenteral nutrition for 1 week reduces ICU-acquired weakness. Crit Care. 2019;55(S2):S94-S5. doi:10.1186/cc12190

77. Hermans G, Casaer MP, Clerckx B, et al. Effect of tolerating macronutrient deficit on the development of intensive-care unit acquired weakness: a subanalysis of the EPaNIC trial. Lancet Respir Med. 2013;1(8):621-629. doi:10.1016/S2213-2600(13)70183-8

78. Vanhorebeek I, Casaer MP, Guiza F, et al. Impact of early versus late parenteral nutrition on morphological and molecular markers of atrophy and autophagy in skeletal muscle of critically ill patients. Crit Care. 2013;17(S2):S96. doi:10.1186/cc12194
Journal of Multidisciplinary Healthcare

\section{Publish your work in this journal}

The Journal of Multidisciplinary Healthcare is an international, peerreviewed open-access journal that aims to represent and publish research in healthcare areas delivered by practitioners of different disciplines. This includes studies and reviews conducted by multidisciplinary teams as well as research which evaluates the results or conduct of such teams or healthcare processes in general. The journal
Dovepress

covers a very wide range of areas and welcomes submissions from practitioners at all levels, from all over the world. The manuscript management system is completely online and includes a very quick and fair peer-review system. Visit http://www.dovepress.com/testimonials. php to read real quotes from published authors. 